\title{
INTERVENÇÃO DOS ESTADOS UNIDOS NA POLÍTICA LOCAL DE PERNAMBUCO ATRAVÉS DO ACORDO DE EDUCAÇÃO DA ALIANÇA PARA O PROGRESSO (1961-1964)
}

\author{
UNITED STATES INTERVENTION IN THE LOCAL POLICY OF \\ PERNAMBUCO THROUGH THE ALLIANCE FOR PROGRESS \\ EDUCATION AGREEMENT (1961-1964)
}

Leonardo Laguna Betfuer Mestre em História Econômica Universidade de São Paulo - USP. São Paulo, SP - Brasil. leonardobetfuer.historia@gmail.com

\begin{abstract}
Resumo: O presente artigo analisa o uso político da Educação feito pelos Estados Unidos, através da Aliança para o Progresso, para interferir na política do estado de Pernambuco. Isso foi feito por meio da assinatura de um convênio de Educação com o governador Cid Sampaio (UDN), com o objetivo de favorecer o seu governo e ingerir nas eleições estaduais de 1962. Reportagens da época levavam o governo dos Estados Unidos a crer que a região Nordeste e Pernambuco, especificamente, eram locais perigosos devido a pobreza e as forças políticas e sociais que disputavam o poder. Sugestionada pela Revolução Cubana (1959), a administração Kennedy (1961-1963) lançou a Aliança para o Progresso, um programa de ajuda econômica para desenvolver a América Latina, apoiar regimes democráticos, e promover a melhoria da qualidade de vida da população, contra a subversão comunista. Aos olhos dos Estados Unidos, as eleições de 1962 para o governo do estado de Pernambuco, disputada entre João Cleofas (UDN) e Miguel Arraes (PST), metaforizaram um conflito entre liberdade e comunismo, respectivamente. Após a vitória de Arraes, os Estados Unidos passaram a dificultar o pagamento das verbas do convênio de educação e muito pouco foi feito de fato, além de propaganda política.
\end{abstract}

Palavras-chave aliança para o progresso; Brasil e Estados Unidos; guerra fria; Pernambuco; Educação.

Abstract: This paper analyzes the political use of Education made by the United States, through the Alliance for Progress, to interfere in the politics of the state of Pernambuco. This was done by signing an Education agreement with Governor Cid Sampaio (UDN), with the aim of favoring his government and interfering in the 1962 state elections. Reports at the time led the United States to believe that the Northeast region and Pernambuco, specifically, were dangerous places due to poverty and the political and social forces that vied for power. Influenced by the Cuban Revolution (1959), the Kennedy administration (1961-1963) launched the Alliance for Progress, an economic aid program to develop Latin America, support democratic regimes, and promote the improvement of the population's quality of life, against communist subversion. In the eyes of the United States, the elections for the government of the state of Pernambuco between João Cleofas (UDN) and Miguel Arraes (PST) metaphorized a conflict between freedom and communism, respectively. After the victory of Arraes, the United States began to make it difficult to pay the funds of the education agreement and very little was actually done, besides political propaganda.

Keywords: alliance for progress; Brazil and United States; cold war; Pernambuco; Education.

Para citar - ABNT NBR 6023:2018

BETFUER, Leonardo Laguna. Intervenção dos Estados Unidos na política local de Pernambuco através do acordo de educação da aliança para o progresso (1961-1964). Cadernos de Pós-graduação, São Paulo, v. 20, n. 2, p. 99-114, jul./dez. 2021. Disponível em: https://doi.org/10.5585/cpg.v20n2.20074. 
Introdução

O sucesso da Revolução Cubana (1959) despertou a atenção dos Estados Unidos para a América Latina e, especialmente, para a região Nordeste do Brasil. Reportagens da época faziam crer que a região estava prestes a explodir em revoluções aos moldes de Cuba. Assim, o governo de John F. Kennedy (1961-1963) fez da região um dos focos do seu recém-lançado programa de ajuda econômica para a América Latina, a Aliança para o Progresso (LEACOCK, 1990; TAFFET, 2007).

O Brasil era visto como um país chave para o sucesso do programa devido a suas proporções continentais e a seu contingente populacional (LEACOCK, 1990). Além disso, o país também era considerado como um aliado histórico no continente (BURNS, 1966).

A Aliança previa investimentos que chegariam a US $\$ 20$ bilhões em uma década para promover crescimento econômico e reforma política. Em troca do apoio da Aliança, os regimes locais deveriam respeitar as instituições democráticas e promover políticas de incremento do padrão de vida da população latino-americana (TAFFET, 2007; LOUREIRO, 2014).

Estudiosos enfatizam que, no Brasil, os fundos da Aliança teriam sido usados como uma ferramenta para desestabilizar o governo do Presidente João Goulart, particularmente quando se tratava de transferir recursos para governadores estaduais que se opunham ao presidente por meio de uma política conhecida como Ilhas de Sanidade (LOUREIRO, 2017; TAFFET, 2007; LEACOCK, 1990). Essa campanha política contribuiu para o golpe que inaugurou a ditadura civilmilitar no Brasil em março de 1964.

Inspirados pelo sucesso da Revolução Cubana no combate ao analfabetismo, a Aliança para o Progresso prometia erradicá-lo na América Latina até os anos 1970. No Brasil, entre 1958 e 1964, as campanhas de alfabetização ganharam destaque por questões eleitorais, uma vez que o direito ao voto era restrito aos cidadãos alfabetizados. Pernambuco, Rio Grande do Norte e Sergipe, por exemplo, desenvolveram programas de alfabetização baseados, principalmente, no método desenvolvido por Paulo Freire. Apesar do compromisso com a erradicação do analfabetismo que a Aliança pregava, o interesse estadunidense pela educação em Pernambuco se deu no contexto da disputa eleitoral para o governo do estado em 1962 (KIERKENDALL, 2010).

A educação depende da luta pelo poder político, pois se configura em um importante instrumento ideológico. Aqueles que detém o poder político são responsáveis por definir a política educacional e o conteúdo ideológico dos programas educacionais. Esses governantes, são ainda responsáveis por buscar recursos por meio de convênios e acordos (PAIVA, 2003). É nesse contexto que a Aliança para o Progresso se apresenta como um programa de ajuda econômica, e como 
uma arma de combate ideológico capaz de "conquistar corações e mentes" por meio da sua presença no campo educacional.

Este artigo argumenta que, em Pernambuco, a Aliança para o Progresso foi utilizada para interferir na política local. Isso foi feito especificamente por meio da assinatura de um acordo na área da Educação entre o governo Cid Sampaio (UDN) e o governo dos Estados Unidos. O convênio de Educação previa a alfabetização de cerca de 150.000 adultos, dando-lhes noções de agricultura, higiene, de vida doméstica e de habilidades profissionais e noções de civismo. Previa o treinamento de professores primários, monitores, supervisores e instrutores de alfabetização de adultos. Na base desse acordo, a real intenção dos Estados Unidos era favorecer a administração Sampaio na disputa pela sucessão ao governo do estado. Fracassado o plano, os Estados Unidos passaram a dificultar a concretização do acordo de educação durante o governo de Miguel Arraes.

\section{O clima político e social em Pernambuco}

Na segunda metade da década de 1950, em Pernambuco, a mobilização dos trabalhadores rurais por melhores condições de vida ganhou fôlego e passou a ser tema da imprensa. Nesse período surgiu a primeira Liga Camponesa. Moradores do engenho Galileia, em Vitória de Santo Antão, município de Pernambuco, localizado na região da Mata, formaram a Sociedade Agrícola e Pecuária dos Plantadores de Pernambuco (SAPPP). Essa entidade nasceu com fins assistenciais, dentre os quais, o de fornecer auxílio funerário, uma vez que, quando um trabalhador morria tinha de ser velado em um caixão da prefeitura, que depois era devolvido para ser reutilizado. O corpo era enterrado em um buraco. Essa prática inspirou o título do livro "sete palmos de terra e um caixão", de Josué de Castro (1975), e se refere ao desejo dos trabalhadores rurais de terem direito a um caixão e a um enterro decente. Oscar Beltrão, dono do engenho Galileia, que de início apoiou a associação e foi nomeado seu presidente de honra, ao ser alertado sobre o caráter "subversivo" da associação, ordenou sua dissolução. Os trabalhadores rurais não acataram as ordens do patrão e, buscaram a ajuda do advogado e deputado estadual Francisco Julião, do Partido Socialista Brasileiro (PSB) (LIMA, 2005; BARROS, 2017).

Francisco Julião passou então a ser o principal líder da Liga Camponesa. A luta que se seguiu terminou com a aprovação, em 1959, do projeto de lei de desapropriação do Engenho Galileia. Essa foi a primeira vez em que houve uma desapropriação para fins de reforma agrária no Brasil. Seguindo o exemplo dos moradores do engenho Galileia, outras Ligas Camponesas surgiram no Nordeste, principalmente no estado da Paraíba, o que elevou o nível de atenção, tanto das elites locais, quanto dos Estados Unidos. Em 1961, as Ligas contavam com cerca de 10 mil associados, distribuídos em 40 delegacias, no estado de Pernambuco (LIMA, 2005; BARROS, 2017). 
Segundo Abreu e Lima (2005, p. 31), no início dos anos 1960, as Ligas Camponesas sofreram grande influência da Revolução Cubana, o que teria lhe provocado "uma grande virada política e ideológica”. As Ligas passaram a considerar ser possível alcançar o socialismo sem etapas, em oposição a visão do Partido Comunista do Brasil (PCB), para quem o socialismo deveria ser atingido através do jogo democrático, em aliança com a burguesia nacional. Essa virada ideológica se deu após a visita de Francisco Julião a Cuba, em 29 de março de 1960. Após a tentativa de invasão de Cuba pelo governo Kennedy, em 1961, as Ligas iniciaram treinamentos de guerrilha em Dianópolis, Goiás (LIMA, 2005). O campo de treinamento acabou ocupado pelas forças armadas pouco tempo depois, mas exemplifica a mudança no direcionamento político e ideológico das Ligas.

Bernard José Pereira Alves (2018), argumenta que as Ligas Camponesas tiveram um relacionamento próximo a Fidel Castro. Segundo o autor, o próprio Fidel sugeriu uma reorganização na estrutura da organização. As ligas deveriam ter três estruturas: a militar, a política e a das massas, lideradas respectivamente por Adalto Freire, Clodomir Morais e Francisco Julião. Moniz Bandeira (1978, p. 305) afirma que o governo cubano "sustentou" as Ligas Camponesas e "forneceu-lhe os recursos para a luta armada no Nordeste"

Esses acontecimentos faziam de Pernambuco um dos estados com maior mobilização social e de maior potencial revolucionário. Os trabalhos de Joseph Page (1972), Pablo Porfírio Dias (2008), Vandeck Santiago (2016) e Arthur Victor Gonçalves Gomes de Barros (2017) convergem nesse sentido. Para esses autores, na década de 1950 e início de 1960, a mobilização social e o potencial processo revolucionário eram estimulados pela extrema pobreza. Para eles, o estado de Pernambuco foi representado como "um lugar perigoso, onde a pobreza somada à atuação de grupos de esquerda estaria produzindo desordem social e preparando uma revolução comunista" (PORFÍRIO, 2008, p. 12).

No plano institucional, a política no estado foi marcada pelo predomínio político do Partido Social Democrata (PSD). O PSD era composto majoritariamente por membros da burocracia estatal e por coronéis do Agreste e do Sertão, sobretudo aqueles vinculados à oligarquia algodoeira e pecuarista. "Do grande coronel ao pequeno produtor, o mundo rural se articulava no PSD" (PANDOLFI, 1984, p. 99). O principal nome da política no estado era Agamenon Magalhães. O PSD era o partido a ser batido em Pernambuco.

A União Democrática Nacional (UDN) foi o principal partido a fazer frente a hegemonia pessedista em Pernambuco. No estado, a UDN tinha como principal característica a oposição a Agamenon Magalhães. Ali, em alguns momentos, por questões regionais, a UDN chegou a apoiar Getúlio Vargas para combater o PSD, contrariando determinações do partido em nível nacional. 
O partido congregava os usineiros da Zona da Mata, membros da oligarquia retirados do poder pelo Golpe de 1930 e por alguns setores da classe média (PANDOLFI, 1984).

Após a derrubada da oligarquia pessedista, os movimentos sociais ganharam força, ao mesmo tempo em que nenhum partido foi capaz de dominar politicamente o estado. De acordo com Pandolfi (1984) "Fora do poder, o pessedismo deix[ou] seu papel de principal ator político". A partir de 1958, um novo quadro político se abriu com a vitória da chapa Oposições Unidas.

O Partido Comunista Brasileiro (PCB) teve uma presença marcante, principalmente na capital do estado. Prova da sua força foi o fato de nas eleições presidenciais de 1945 o candidato comunista Iedo Fiuza ter sido o vencedor na grande Recife. Na mesma ocasião, o partido elegeu três deputados federais (PANDOLFI, 1984).

Em 1955, mesmo na ilegalidade, o Partido Comunista foi fundamental para a formação da Frente do Recife. Tratava-se de uma aliança político-partidária entre comunistas, socialistas e correntes de esquerda independentes, com base em um programa de cunho democrático e nacionalista. A primeira eleição na qual a Frente do Recife participou da disputa foi o pleito para prefeito do Recife. A capital havia acabado de receber autonomia para escolher seus governantes por meio de sufrágio eleitoral. Durante o Estado Novo, o prefeito da capital era nomeado pelo interventor estadual. O candidato da Frente do Recife, o socialista Pelópidas Silveira (PSB), foi eleito prefeito do Recife (PANDOLFI, 1984; SOARES, 1982).

Em 1957, a UDN se juntou à Frente do Recife formando a chapa Oposições Unidas. Além da UDN, os partidos que compunham a chapa eram o Partido Socialista Brasileiro (PSB), o Partido Trabalhista Nacional (PTN), o Partido Trabalhista Brasileiro (PTB) e o Partido Social Progressista (PSP), além dos comunistas. Pelo lado da UDN, houve resistência com relação ao apoio dos comunistas à chapa, e também com relação à escolha do nome de Cid Sampaio para disputar as eleições para o governo do estado, que ocorreriam em 1958. Alguns setores da UDN preferiam um nome mais moderado. É importante destacar que os próprios comunistas se opuseram a essa hipótese e exigiram a manutenção do nome de Cid Sampaio. Pelópidas Silveira deixou a prefeitura do Recife para concorrer ao cargo de vice-governador pela chapa. Miguel Arraes, deputado estadual pelo PSD, foi o principal coordenador da campanha de Cid Sampaio. Antes do pleito, Arraes deixou o PSD e passou a integrar o Partido Social Trabalhista (PST) (SOARES, 1982).

Ao contrário do que ocorria no nível nacional, onde a UDN era a principal inimiga da esquerda, em Pernambuco, ela contou com o apoio da esquerda contra o PSD. Esse é um dado importante das características partidárias regionais no período, que em muitos casos se diferencia- 
vam da posição dos diretórios nacionais. A partir do pleito presidencial de 1960, a UDN pernambucana passaria a se alinhar ao direcionamento proposto pelo diretório nacional do partido (SOARES, 1982).

Quando o pessedismo foi "excluído do poder e esfacelado politicamente, todo o tradicional sistema partidário pernambucano se desagrega" (PANDOLFI, 1984, p. 199).

Nesse sentido, os governos de Cid Sampaio, UDN (1959-1962), e Miguel Arraes, PST (1963-1964), representam tentativas de ocupar o espaço deixado pelo PSD e são extremamente importantes para a história política de Pernambuco. Cid Sampaio e Miguel Arraes são dois lados de uma mesma moeda, na medida em que ambos crescem politicamente no vácuo de poder deixado pelo fim da hegemonia pessedista no estado. Em um primeiro momento, os dois políticos se uniram contra o PSD, mas a partir da imprevisibilidade do cenário político estadual, sem o PSD no governo, os dois passaram a se opor (PANDOLFI, 1984).

Miguel Arraes, iniciou sua carreira política em 1948 como Secretário da Fazenda do governo Barbosa Lima Sobrinho (PSD) e, em 1950, foi eleito deputado estadual pelo 50 PSD, tendo se desligado do partido apenas em 1958, quando disputou as eleições pelo PST, coligado à Frente do Recife. Em 1958, foi um dos principais articuladores da campanha de seu concunhado Cid Sampaio, ao governo do estado. $\mathrm{Na}$ administração Sampaio, ele ocupou o cargo de Secretário da Fazenda até 1959, quando se desligou para concorrer à prefeitura do Recife, contando para isso com o apoio político de Cid Sampaio.

Usineiro, filho de senhores de engenho e com família de trajetória política relevante, Cid Sampaio tem um histórico mais antigo de oposição ao PSD. Os irmãos de Cid fizeram longa carreira política. Alde Sampaio foi deputado constituinte em 1934 e 1946. Lael Sampaio ocupou secretárias nos governos de Barbosa Lima Sobrinho (PSD) e Cid Sampaio (UDN). Os irmãos foram simpáticos à Revolução de 1930 e se opuseram ao Estado Novo. Os três participaram ativamente na criação da UDN e, em 1958, Cid e Alde foram eleitos pela UDN, em coligação na chapa Oposições Unidas, governador e deputado federal, respectivamente.

Para Joseph Page (1972), Cid Sampaio não era o tipo de ator político capaz de liderar uma ruptura política com implicações transformadoras no estado. Ainda segundo esse autor, assim que foi o eleito, o governador buscou se afastar das correntes de esquerda que o apoiaram. No entanto, Dulce Pandolfi (1984) destaca que Cid Sampaio buscou manter o equilíbrio entre seu governo e os grupos de esquerda. Prova disso teria sido a nomeação de uma assessoria sindical com líderes abertamente ligados ao Partido Comunista. Para a autora, "isso representava um apelo à continuidade da aliança, dentro dos marcos de controle do estado" (PANDOLFI, 2000, p. 200). 
Ainda em 1959, Cid enfrentou duas questões importantes. A primeira delas, relacionada ao campo, dizia respeito à desapropriação do engenho Galileia para reforma agrária. Tal medida foi criticada pelos setores mais tradicionais do estado. A segunda, estava relacionada ao debate em torno da sucessão para a prefeitura do Recife. Segundo Pandolfi (1984), a indicação de Miguel Arraes não agradava o governador pernambucano. Porém, Cid Sampaio reuniu cerca de quinhentos comerciantes e industriais para comunicar-lhes que apoiava Arraes. É somente nas eleições presidenciais de 1960, que o distanciamento entre o governador Cid Sampaio e Miguel Arraes ganha evidência. No entanto, os dois só romperiam publicamente em 1962, no contexto da disputa pelo governo do estado.

Cid Sampaio foi um crítico da autonomia da SUDENE, que em muitos momentos se contrapôs aos interesses da administração local. Em reunião do Conselho Deliberativo do órgão, chegou a afirmar que "se ela continuasse agindo paralelamente aos serviços estaduais, superando os governos, era preferível que o Congresso Nacional decretasse de uma vez intervenção no Nordeste" (PANDOLFI, 1984, p. 201). Em 1962, ao romper com Cid Sampaio, a esquerda o acusou de ter se envolvido com o Instituto Brasileiro de Ação Democrática (IBAD) e com a Aliança para o Progresso, o que era fato incontestável. Além disso, o acusavam de apoiar o imperialismo contra os movimentos sociais e a SUDENE (PANDOLFI, 1984).

O governo norte-americano, por sua vez, via em Cid Sampaio um de seus aliados mais fortes no Nordeste. Eles acreditavam que os comunistas, aproveitando o sofrimento econômico e a miséria humana na região, estavam trabalhando com rapidez e eficácia na subversão regional. O sucesso ou falha de Cid Sampaio em realizar seu programa de desenvolvimento era considerado crucial para a política externa norte-americana na América Latina.

Na sucessão estadual de 1962, o PSD, marginalizado do poder, precisava se alinhar com outras agremiações para a disputa. No centro da chapa Oposições Unidas ocorreu uma polarização. João Cleofas foi indicado candidato pela UDN e Miguel Arraes pelo PST, este último com apoio da Frente do Recife. A candidatura de Arraes para o governo do estado cresceu ainda em 1961. José Ermínio de Moraes, industrial, candidato ao senado por Pernambuco, financiou a campanha de Arraes ao governo. Nessa época, Pernambuco vivia um clima de radicalização política, com reflexos no panorama nacional, que já se encontrava marcado pela polarização entre as forças da esquerda e as conservadoras (PANDOLFI, 1984).

A polarização eleitoral entre Comunismo e Democracia partiu da própria UDN e contou com o apoio do jornal Diário de Pernambuco. Num primeiro momento o jornal defendeu a união da UDN e PSD em torno da candidatura de João Cleofas. Mas essa tese obteve pouca receptividade, dado o histórico de oposição entre os dois partidos (PANDOLFI, 1984). 
O governo dos Estados Unidos contribuiu para alimentar essa polarização. O possível sucesso de Miguel Arraes em Pernambuco e a renúncia de Jânio Quadros levaram os Estados Unidos a realizar acordos diretamente com o governador Cid Sampaio, ultrapassando a autoridade da SUDENE. Os Estados Unidos acreditavam que Pernambuco poderia ser um símbolo de sucesso da Aliança no Nordeste se seus projetos pudessem ser implementados em tempo.

\section{O uso político da educação para vencer a guerra fria em Pernambuco}

As condições de vida da população pobre de Pernambuco e, especificamente do Recife, chamavam a atenção da imprensa nacional e internacional. Recife era tida como a quarta pior cidade do mundo, superada apenas por três cidades africanas, em termos de pobreza e desigualdade (CASTRO, 1984). Vandeck Santiago (2016) e Arthur Barros (2017) destacaram em seus trabalhos que a cobertura da imprensa sobre as condições sociais no estado teria sido uma das motivações da criação do programa Aliança para o Progresso. Ambos autores concordam que a série de reportagens produzidas, em outubro de 1960, pelo correspondente do New York Tymes, Tad Szulc, teriam grande influência sobre a opinião pública norte-americana e, também, sobre o Presidente John Kennedy.

Antes mesmo do lançamento oficial da Aliança para o Progresso, em fevereiro de 1961, o Presidente Kennedy enviou ao Nordeste do Brasil uma delegação para estudar a possibilidade de trabalhar junto à Superintendência para o Desenvolvimento do Nordeste (SUDENE) - órgão criado em 1959 com o objetivo de desenvolver a região. Em abril de 1962, Brasil e Estados Unidos assinaram o "Acordo do Nordeste". Por meio desse acordo, os Estados Unidos se comprometiam a investir o valor de US\$ 131 milhões (US\$ 831 milhões em valores atualizados pelo Indíce de Preços do Consumidor dos Estados Unidos), no Nordeste.

O acordo definia que o governo norte-americano suplementaria os esforços do Brasil no desenvolvimento do Nordeste. Para tanto, deveriam executar um programa de ação imediata destinado a obter resultados rápidos na satisfação das mais urgentes necessidades do povo do Nordeste. (ROETT, 1972; SANTIAGO, 2016).

A SUDENE e a United States Agency of International Development (USAID) foram as agências escolhidas para administrar os recursos do acordo. O Acordo do Nordeste autorizava o estabelecimento de um escritório da USAID em Recife, já que a sede da SUDENE estava localizada em Pernambuco. A SUDENE estava autorizada a concluir acordos sobre projetos e empréstimos. "As atividades compreendidas nesses projetos poderiam ser administradas pela SUDENE ou por qualquer outra repartição ou órgão escolhido por mútuo acordo” (ROETT, 1972). Nos casos que fos- 
sem indicados pelo governo brasileiro, outras repartições poderiam ser autorizadas a concluir acordos sobre projetos, ou outros diretamente com a USAID, sendo autorizadas a receber empréstimo ou donativos (ROETT, 1972; SANTIAGO, 2016).

Riordan Roett (1972) destaca que a principal dificuldade no início da Aliança para o Progresso, no Nordeste, estava na interpretação da possibilidade de a USAID realizar acordos sem a anuência da SUDENE. Os Estados Unidos interpretavam que podiam celebrar acordos com outras agências brasileiras sem a participação da SUDENE. Esta, por sua vez, entendia que para manter sua posição na região, ela própria deveria aprovar, estar envolvida, ou designar a agência competente em todos os projetos. "Para os Estados Unidos, o acordo significava que eles poderiam começar a combater diretamente a ameaça comunista que haviam identificado no Nordeste" (ROETT apud PAGE, 1972, p. 95). O governo norte-americano utilizou essa interpretação para estabelecer acordos diretos com governos estaduais, sem a participação da SUDENE.

Nesse sentido, Pernambuco foi o primeiro estado a celebrar acordos diretos com o governo dos Estados Unidos. Ainda em 1961, ocorreu um intenso debate entre o Departamento de Estado e a embaixada norte-americana no Brasil a respeito de um programa de construção de escolas que evidenciasse a presença dos Estados Unidos no Nordeste. A princípio, o estado do Rio Grande do Norte foi considerado a primeira opção. Aluísio Alves iniciava seu mandato como governador e seu perfil era interpretado como o tipo político reformista e modernizador com quem os Estados Unidos poderiam trabalhar dentro do espírito da Aliança para o Progresso. Porém, o consulado norteamericano no Recife sugeriu que o programa fosse levado a cabo no estado de Pernambuco. De acordo com o consulado, além de Pernambuco ser um estado importante, um programa bemsucedido receberia publicidade e poderia favorecer ao candidato de Cid Sampaio (UDN) nas eleições de outubro de 1962 (ROETT, 1972, p. 74).

As negociações entre a USOM (predecessora da USAID) e o governo de Pernambuco foram abertas em setembro de 1961. Um entendimento sobre a ajuda dos Estados Unidos à educação foi alcançado somente em maio de 1962, quando então as negociações entre os Estados Unidos e o governo de Pernambuco vieram a público. O secretário de educação e cultura de Pernambuco, Lourival Vilanova, anunciou que "o governo do estado estava próximo de celebrar um acordo de combate e redução do analfabetismo" (ROETT, 1972, p. 75). Havia por parte do consulado norteamericano no Recife, “a esperança de que o acordo atraísse votos suficientes para garantir a eleição, em outubro, do candidato do governo estadual" (ROETT, 1972, p. 75).

No dia 08 de junho de 1962, foi assinado, pelo embaixador Lincoln Gordon e o governador Cid Sampaio, o acordo de educação Aliance for Progress Elementary and Basic Education. Esse acordo previa a doação de US\$ 1 milhão, aproximadamente Cr\$350 milhões, para a construção de 1800 
salas de aulas, com 250 mil matrículas para adultos e crianças, a ser executado em 3 anos (BETFUER, 2019).

$\mathrm{Na}$ época, o então governador Cid Sampaio celebrou contratos compreendendo as seguintes áreas: educação, saúde, habitação popular e colonização (BARROS, 2017). Ainda em 24 de setembro de 1962, às vésperas do pleito para governador, foi feito um empréstimo à Companhia Pernambucana de Borracha (COPERBO), coração do projeto industrial de Cid Sampaio, no valor de US\$3,4 milhões, na tentativa de influenciar positivamente a imagem de seu sucessor João Cleofas, da UDN (ROETT, 1972).

O convênio de Educação previa a alfabetização de cerca de 150.000 adultos, dando-lhes noções de agricultura, higiene, de vida doméstica e de habilidades profissionais e noções de civismo. O acordo ainda previa a promoção de treinamento para 8.000 professores primários, monitores, supervisores e instrutores de alfabetização de adultos e o treinamento, nos Estados Unidos ou outros países, de 25 candidatos que viriam a trabalhar no programa de treinamento de professores (COELHO, 2012).

O acordo de educação envolvia as seguintes partes: o estado de Pernambuco, a Comissão Especial dos Acordos sobre Produtos Agrícolas (CEAPA), a USAID/Brazil, o Ministério da Educação e Cultura do Governo do Brasil e o Representante do Governo Brasileiro para a Coordenação dos Programas de Assistência Técnica (Ponto IV) (COELHO, 2012).

Para a execução do programa de cooperação, o estado de Pernambuco criou o Serviço Educacional de Pernambuco, subordinado à Secretária de Educação e Cultura do estado de Pernambuco. O Secretário de Educação de Pernambuco era o Diretor do Serviço Educacional. O Diretor da USAID/Brazil designaria um assessor em educação da USAID para representa-la junto ao Serviço Educacional. Cabia ao Secretário de Educação e Cultura aprovar a designação do representante (COELHO, 2012).

O estado de Pernambuco deveria arcar com a maior parte dos investimentos, por meio da concessão de terrenos, materiais e serviços, pessoal qualificado, salários e ajuda de custos para bolsistas, instalação de escritórios, guarda e conservação de material, serviços de engenharia para a construção de escolas (COELHO, 2012).

Em agosto de 1962, o estado de Pernambuco recebeu a importância de Cr\$132,5 milhões, para a primeira etapa do projeto de construção de 144 salas de aula. Cada sala de aula custava em média Cr\$ 600.000 cruzeiros. Os governos municipais doavam os terrenos para a construção das salas de aula (BETFUER, 2019, p. 103). A distribuição das salas de aula privilegiava as cidades da região metropolitana, o que se justifica pela densidade demográfica, mas que também pode indicar uma predileção pelos maiores colégios eleitorais (BARROS, 2017). 
Nas eleições de 1962 para governador do estado de Pernambuco, Miguel Arraes foi o vencedor. Logo que assumiu, em 31 de janeiro de 1963, o governador eleito anunciou que sua administração não negociaria diretamente com nenhum governo estrangeiro. Todas as negociações de assistência externa deviam ser canalizadas pelo Ministério das Relações Exteriores ou pelo seu representante, no caso a SUDENE. Arraes ainda instaurou uma Comissão de Inquérito para investigar todos os acordos assinados entre o estado de Pernambuco e o governo dos Estados Unidos (BARROS, 2017).

Segundo Loureiro (2017), Arraes nunca se negou publicamente a receber a ajuda econômica da Aliança para o Progresso, apesar das críticas direcionadas ao programa. Contudo, a visão do governo norte-americano sobre o governador era bastante negativa. Chama a atenção o fato de que de estado modelo e um dos principais receptores de recursos da Aliança, em 1962, junto com a Guanabara e o Rio Grande do Norte, Pernambuco sofreu uma queda brusca no recebimento de recursos durante a administração Arraes (LOUREIRO, 2017).

A biografia elaborada pelo Consulado Geral norte-americano refletia hostilidade ao governador ao descrevê-lo como um "esquerdista extremista e ultranacionalista, eleito com o apoio do Partido Comunista, com o qual ele sempre manteve uma relação de trabalho muito próxima" (CONSULADO DOS EUA, 1963). Segundo esse relatório, ao tomar posse do cargo, Arraes passou a nomear muitos comunistas e extremistas esquerdistas-nacionalistas para cargos de responsabilidade e influência dentro de sua administração (CONSULADO DOS EUA, 1963).

O governo norte-americano acreditava que a relação com Arraes deveria ser feita com cautela. Em relatório enviado por Delgado Árias ao Secretário de Estado, Dean Rusk, datado de 7 de fevereiro de 1963, o consulado recomendava que a aproximação de Arraes fosse feita com "cuidado" e que este era totalmente antagonista à presença norte-americana no Brasil e à Aliança para o Progresso. Entre as evidências constavam a associação passada e atual de Arraes com os comunistas. O cônsul geral, Delgado Árias, em seu relatório, ainda fez menções às declarações contrárias à Aliança para o Progresso feitas pelo governador em suas conferências de imprensa e em seu discurso inaugural, e criticou a nomeação de comunistas, pró-comunistas e elementos de posição nacionalista de extrema esquerda para cargos do governo estadual. "Os sentimentos de Arraes quanto aos Estados Unidos e a Aliança para o Progresso não são fruto de desentendimento, mas de uma opinião formada ao longo dos anos" (CONSULADO DOS EUA, 1963). Árias concluiu que "não existe a possibilidade de estabelecer uma relação construtiva com Arraes", ainda que não acreditasse que ele fosse controlado pelos comunistas, ou mesmo que cooperasse com eles (CONSULADO DOS EUA, 1963). 
Em março de 1963, o relatório da Comissão de Inquérito instaurado, pelo governador Miguel Arraes, para investigar os acordos da Aliança com o governo do estado de Pernambuco concluiu que houve interferência da USAID/Brasil na política interna do país. Ele recomendava que o estado de Pernambuco deveria denunciar os acordos por flagrante inconstitucionalidade; que o estado não deveria admitir nenhuma forma de alienação de seus órgãos administrativos (como a criação de entidades paralelas, por exemplo) para a codireção de programas específicos (COELHO, 2012).

O relatório também criticou a excessiva propaganda em torno da Aliança. De acordo com o relatório, havia muita propaganda vinculando os projetos à Aliança, o que "criava uma mística" de transformação em torno do programa, sem dar o crédito devido a contrapartida do estado. Pernambuco não deveria admitir que os projetos total ou parcialmente financiados por ajuda externa fossem elaborados, dirigidos ou controlados por representantes de qualquer órgão estrangeiro. O estado poderia firmar acordos dentro da estrutura da Aliança para o Progresso, desde que através do órgão federativo competente - a SUDENE. O estado de Pernambuco deveria ainda alertar as autoridades competentes e a opinião pública quanto ao uso dirigido com objetivos políticos, de vultosos recursos por parte da USAID sem qualquer controle do governo Federal, submetendo a política econômica dos governos locais ao Departamento de Estado (COELHO, 2012).

Ao analisarmos as partes integrantes dos convênios com o estado de Pernambuco, observamos a ausência da SUDENE nos convênios de habitação, educação e colonização. No entanto, há a participação da Comissão de Coordenação da Aliança para o Progresso (COCAP) e, no caso do convênio de educação, do próprio Ministério da Educação e Cultura (COELHO, 2012).

É fato que o órgão federal responsável pela administração de projetos de desenvolvimento no Nordeste era a SUDENE, porém havia outro órgão federal que participara dos convênios, no caso a COCAP. O próprio Celso Furtado, após a denúncia de Arraes na reunião do Conselho Deliberativo da SUDENE, buscou minimizar o caso ao dizer que os problemas anteriores já haviam sido resolvidos e que não haviam motivos para interromper a ajuda econômica. Isso é sintomático, pois nem o Superintendente da agência "prejudicada" estava disposto a hostilizar a Aliança para o Progresso, enquanto o governador de Pernambuco buscou capitalizar politicamente o episódio, ainda que não pretendesse abrir mão dos recursos da Aliança.

Os Estados Unidos, por sua vez, buscaram dificultar a liberação de algumas parcelas referentes aos acordos de educação e colonização. O governo Arraes, em resposta, atrasou a entrega de algumas dessas obras. A relação entre os dois governos foi bastante conturbada no que diz respeito à Aliança para o Progresso. É certo que o nacionalismo de Arraes possuía uma forte retórica 
anti-imperialista e que os Estados Unidos estavam convencidos de que Arraes era um "extremistaesquerdista", termo que aparece nos documentos oficiais norte-americanos.

Em fevereiro de 1963, as três primeiras escolas construídas com verbas da Aliança foram concluídas: a escola Othon Paraíso, no Cordeiro, Eleonor Roosevelt, no Imbiribeira e Jackeline Kennedy, na Mustardinha. Somente em 20 de agosto de 1963, a quarta escola, construída em Carpina, com capacidade para 100 crianças, ficou pronta. O Diário de Pernambuco acusava o governo Miguel Arraes de estar dificultando a inauguração das escolas construídas pelo convênio com a Aliança para o Progresso. De acordo com o jornal, a escola Eleonor Roosevelt, com 40 salas de aula, encontrava-se pronta e fechada. Arraes justificou que nenhuma escola da Aliança havia sido inaugurada, pois o governo norte-americano não havia realizado os pagamentos das verbas da Aliança, e anunciou que as escolas seriam terminadas, mas com verbas do governo do estado (BETFUER, 2019).

Um relatório de inspeção de campo da USAID para averiguar o status da construção das escolas pernambucanas, de setembro de 1963, mais de um ano após a assinatura do convênio, revelava que muito pouco havia sido feito, como demonstra o trecho abaixo:

7 construções escolares concluída até o ponto de ocupação utilizável; 10 escolas dentro de 75\% da conclusão; 19 escolas dentro de 40\% da conclusão; E 9 escolas não iniciadas ou $25 \%$ concluídas. Dos 59 edifícios concluídos, apenas 3 estavam em uso. Os restantes 56 careciam de professores, móveis e suprimentos. Em muitos casos, as ervas daninhas tinham tomado as escolas (ROETT, 1972, p. 138).

Roett (1972, p. 136) afirma que, de fato, em março de 1963, uma "linha dura" na educação pernambucana começou a ser praticada pelo governo dos Estados Unidos para dificultar o recebimento das prestações do convênio de educação por Miguel Arraes. Fica evidente que os problemas nas relações entre Arraes e o governo norte-americano foram fundamentais para o fracasso da implementação do projeto de educação no estado.

No início de 1964, a embaixada dos Estados Unidos tornou sua posição em relação a Arraes bastante clara. Em relatório, afirmava que o governador havia dado ampla liberdade de ação a elementos comunistas e extremistas radicais do movimento trabalhista, particularmente nas áreas rurais. O relatório prosseguia dizendo que ele não havia tomado nenhuma ação que indicasse a intenção de "cubanizar" ou socializar Pernambuco, mas suas atitudes e expressões de política, no entanto, indicavam claramente que se ele tivesse a oportunidade de exercer o poder no Brasil sua conduta inevitavelmente levaria a cubanização (EMBAIXADA DOS EUA, 1964). 


\section{Considerações finais}

Esse trabalho confirma a tese apresentada por muitos outros historiadores de que a Aliança para o Progresso foi um instrumento de intervenção na política interna dos países da América Latina, utilizado pelos Estados Unidos como arma de combate na Guerra-Fria.

A partir da análise apresentada, fica evidente que a Aliança para o Progresso foi utilizada para interferir na política local. Isso foi feito especificamente por meio da assinatura de um acordo na área da Educação entre o governo Cid Sampaio (UDN) e o governo dos Estados Unidos. O motivo desse acordo seria favorecer a administração Sampaio na disputa pela sucessão ao governo do estado. Fracassado o plano, os Estados Unidos passaram a dificultar a concretização dos projetos de educação durante o governo de Miguel Arraes. Este, por sua vez, combateu a interferência dos Estados Unidos denunciando-a na CPI do IBAD/IPES, de 1963, e no relatório da comissão de inquérito instaurado por seu governo. Após a prisão de Arraes, durante o Golpe Civil-Militar de 1964, os repasses da Aliança ao estado seriam normalizados.

Quanto aos resultados da Aliança para o Progresso no estado de Pernambuco, estes se mostraram pífios. Muito pouco foi realizado e o programa não se mostrou capaz de alterar a condição de vida dos habitantes do estado. Os efeitos da Aliança ficaram restritos ao campo da propaganda política. Primeiro porque buscavam criar uma imagem positiva dos Estados Unidos na região, o que nem sempre funcionou. Em muitos casos, o excesso de logotipos da Aliança estimulou o antiamericanismo (PAGE, 1972). Em segundo lugar, como propaganda política para os governadores estaduais, como foi o caso de Cid Sampaio, que ainda sim não acarretou na vitória deste nas eleições para governo estadual.

\section{Referências}

ALVES, B. J. P. Revisitando as ligas camponesas: lideranças e disputas internas do movimento camponês. REVISTA IDEAS (ONLINE), v. 9, p. 202- 224, 2018. Disponível em: https://revistaideas.ufrrj.br/ojs/index.php/ideas/article/view/142/141. Acesso em: 21/12/2019.

BANDEIRA, L. A. M. Presença dos Estados Unidos no Brasil: dois séculos de história. $2^{\mathrm{a}}$ Ed. Rio de Janeiro: Civilização Brasileira, 1978.

BARROS, A. V. G. de. A pobreza como estopim da revolução: a Aliança para o Progresso em Pernambuco (1959-1964). 2017. Dissertação (Mestrado em História) - Centro de Filosofia e Ciências Humanas, Universidade Federal de Pernambuco, Recife, 2017. Disponível em: https://repositorio.ufpe.br/handle/123456789/28092. Acesso em: 12/03/2019.

BETFUER, L. L. Pernambuco e a Aliança para o Progresso: ajuda econômica regional no Brasil de João Goulart (1961-1964). 2019. Dissertação (Mestrado em História Econômica) - Faculdade de Filosofia Letras e Ciências Humanas, Universidade de São Paulo, São Paulo, 2019. doi:10.11606/D.8.2019.tde-07112019-171552. Acesso em: 07/05/2020. 
BURNS, E. B. The unwritten alliance: Rio-Branco and Brazilian-American relations. New York [Estados Unidos]: Columbia University Press, 1966.

CASTRO, J. Geografia da Fome. Rio de Janeiro: Antares, 1984.

CASTRO, J. Sete palmos de terra e um caixão. Lisboa: Editora Seara Nova, 1975.

COELHO, G. MCP: História do Movimento de Cultura Popular. Recife: Ed. do Autor, 2012.

CONSULADO DOS ESTADOS UNIDOS. Report. Recife to State Department, Mar 23, 1963. Disponível em: https://repository.library.brown.edu/studio/item/bdr:353895/ Acesso em: $29 / 11 / 17$.

CONSULADO DOS ESTADOS UNIDOS. Telegram no 178, Recife to State Department, Feb 07, 1963. Disponível em: https://repository.library.brown.edu/studio/item/bdr:353951/. Acesso em 29/11/2017.

EMBAIXADA DOS ESTADOS UNIDOS. Airgram, Rio de Janeiro to State Department, Dec 17, 1964. Disponível em: https://repository.library.brown.edu/studio/item/bdr:363767. Acesso em: 29/11/17.

KIRKENDALL, A. Paulo Freire and the Cold War Politics of Literacy. University of North Carolina Press, 2010.

LEACOCK, R. Requiem for Revolution: The United States and Brazil, 1961-1969. Kent and London: Kent State University Press, 1990.

LIMA, M. do S. A. e. Construindo o Sindicalismo Rural: lutas, partidos, projetos. $2^{\text {a }}$ Ed. Recife: Ed. Universitária da UFPE, 2005.

LOUREIRO, F. P. Aliança para poucos: ajuda econômica norte-americana para estados brasileiros durante o governo João Goulart (1961-1964). 2017. (Tese de Livre Docência) - Instituto de Relações Internacionais, Universidade de São Paulo, USP, Brasil, 2017.

LOUREIRO, F. P. Empresários, Trabalhadores e Grupos de Interesse: a Política Econômica nos Governos Jânio Quadros e João Goulart (1961-1964). ed. São Paulo: UNESP/FAPESP, 2017.

LOUREIRO, F. P. The Alliance For or Against Progress? US-Brazilian Financial Relations in the Early 1960s. Journal of Latin American Studies 46 (02), 2014, p. 323- 51.

PAGE, J. A Revolução que nunca houve: o Nordeste do Brasil (1955-1964). Rio de Janeiro: Editora Record, 1972.

PAIVA, V. História da educaşão popular no Brasil: educação popular e educação de adultos. São Paulo: Loyola, 2003.

PANDOLFI, D. C. Pernambuco de Agamenon Magalhães. Recife: Fundação Joaquim Nabuco - Editora Massangana, 1984. 
PORFÍRIO, P. F, de A. Pernambuco em perigo: pobreza, revolução e comunismo (1959-1964). 2008. Dissertação (Mestrado em História). Programa de Pós-Graduação em História, Universidade Federal de Pernambuco, Recife, 2008.

ROETT, R. The politics of foreign aid in the Brazilian Northeast. Nashville, TN: Vanderbilt University Press, 1972.

SANTIAGO, V. Pernambuco em chamas: a intervenção dos EUA e o golpe de 1964. Recife: Cepe Editoria, 2016.

SOARES, J. A. A Frente do Recife e o Governo Arraes. São Paulo: Paz e Terra. 1982.

TAFFET, J. Foreign Aid as Foreign Policy. The Alliance for Progress in Latin America. London and New York: Routledge, 2007. 